Rev Bras Psiquiatr, 21 (2), 19999

Livros

\section{Classificação deTranstornos Mentais e de Comportamento da CID-10 - Diretrizes Diagnósticas e de Tratamento para Transtornos Mentais em Cuidados Primários}

Organização Mundial da Saúde. 1998. Porto Alegre: Artes Médicas. 105 páginas. ISBN 85-7307-326-8

Nós, psiquiatras, pouco duvidamos da importância do nosso papel diagnóstico e terapêutico diante de pessoas portadoras de transtornos mentais, principalmente aquelas com transtornos mais graves e debilitantes como a esquizofrenia e outros transtornos psicóticos. No entanto, sabemos também que nossos esforços especializados, por mais valiosos que sejam, são dedicados apenas a uma pequena parcela do total de pessoas que têm suas vidas prejudicadas por algum tipo de transtorno mental. Como já demonstraram diversos estudos epidemiológicos, inclusive alguns realizados no Brasil, a maioria dos portadores de transtornos mentais não se encontra nos ambulatórios e consultórios de psiquiatria, e muito menos nos hospitais psiquiátricos, mas sim na rede básica de saúde, também chamada de rede de cuidados primários. Fazem parte desta rede os serviços de pronto-atendimento, os centros e postos de saúde, os ambulatórios e consultórios de clínica médica, de gastroenterologia, cardiologia, neurologia, etc. E são justamente os médicos — não os psiquiatras - e demais membros das equipes de saúde que atuam na rede de cuidados primários, aqueles que de fato detectam e tratam da maior parte da morbidade psiquiátrica de uma comunidade. Só para se ter uma idéia, calcula-se que cerca de $90 \%$ dos indivíduos com algum tipo de transtorno mental procuram atendimento na rede de cuidados primários, enquanto menos de $10 \%$ deles (certamente aqueles mais graves) recebem atenção na rede especializada de ambulatórios e hospitais psiquiátricos.

Com base nesses fatos, a Organização Mundial da Saúde (OMS) tem feito de tudo ao seu alcance para sensibilizar médicos e demais agentes de saúde para essa difícil tarefa de detectar e tratar também os transtornos mentais. É dentro da ampla iniciativa de facilitar esta tarefa que a OMS compila e publica pela primeira vez, em 1996, essas Diretrizes Diagnósticas e de Tratamento para Transtornos Mentais em Cuidados Primários, agora disponíveis em português. Para um bom conhecedor do capítulo $\mathrm{V}$ (dos transtornos mentais) da décima versão da Classificação Internacional de Doenças (CID-10), basta folhear rapidamente este pequeno livro para notar que as diretrizes diagnósticas para a rede de cuidados primários nele apresentadas são versões resumidas das diretrizes propostas na CID-10. Nota-se, por exemplo, o mesmo marcador F32 para depressão, ou F10 para transtornos por uso de álcool. No entanto, há várias inovações, algumas até audaciosas. Com apresentação bastante didática e convidativa, neste livro há duas páginas para cada um dos transtornos mentais: na primeira delas, a página de diretrizes diagnósticas, sempre na página à esquerda de quem abre o livro, há

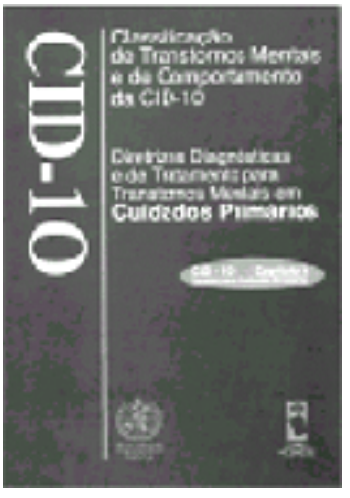
um resumo das principais queixas apresentadas pelos pacientes, um resumo dos aspectos diagnósticos relevantes e alguns dados para um diagnóstico diferencial. A segunda página, sempre à direita, traz a novidade deste livro: ela contém as diretrizes de tratamento, com informações essenciais para o paciente e familiares, recomendações para os mesmos tentarem manejar os sintomas, alguns dados sobre o uso de medicação e até sugestões de quando consultar um especialista. Os apêndices são bem interessantes, contendo inclusive um índice de sintomas e dois fluxogramas para auxiliar a tarefa diagnóstica.

Apesar de claramente dirigido à equipe de cuidados primários de saúde, este livro deveria fazer parte da biblioteca pessoal de todos os psiquiatras. Poderia, quem sabe, de início, servir como facilitador da comunicação entre estes e os demais profissionais que atuam nesta vasta rede de atendimento primário. Todos teriam muito a ganhar com esta maior aproximação, principalmente nós, psiquiatras, que temos muito o que aprender com os nossos colegas que de fato cuidam da maioria dos transtornos mentais da população. Sabemos que, com muita freqüência, esses colegas prescrevem psicotrópicos e utilizam intervenções psicoterápicas de vários tipos, principalmente de caráter suportivo. Com muita freqüência também, a reação dos psiquiatras é crítica, dizendo que as doses de psicotrópicos são subterapêuticas, e que a psicoterapia é inadequada. Será mesmo? Onde está a evidência que os transtornos que o psiquiatra diagnostica são os mesmos que o clínico geral atende na sua rotina diária? Será que a evidência que justifica as intervenções terapêuticas para os transtornos mentais pode ser tão simplesmente transportada para os transtornos observados na rede primária? O tema é complexo, e este livro está longe de resolvê-lo. Mas se ele puder ser útil também para os psiquiatras, terá mais do que cumprido o seu objetivo principal.

Eduardo Iacoponi

Departamento de Psiquiatria e Psicologia Médica da Faculdade de Ciências Médicas da Santa Casa de São Paulo 


\section{Psiquiatria Geriátrica}

Por Ewald W. Busse e Dan G. Blazer. 1999. Porto Alegre: Editora Artes Médicas Sul. 496 páginas. ISBN 85-7307-486-8

Este livro, cujo título original é Textbook of Geriatric Psychiatry (publicado pela American Psychiatry Press em 1996) está dividido em quatro partes: Ciência Básica da Psiquiatria Geriátrica, Avaliação Diagnóstica do Paciente Idoso, Transtornos Psiquiátricos no Idoso e Tratamento dos Transtornos Psiquiátricos no Idoso.

A primeira metade do livro oferece ao leitor uma perspectiva histórica da evolução das teorias biológicas e psicológicas do envelhecimento. O capítulo sobre fatores sociais e econômicos relacionados aos transtornos psiquiátricos no idoso é muito interessante, pois chama a atenção para a importância destes no planejamento de sistemas de saúde, em que o modelo médico tradicional pode não ser tão adequado para o tratamento do idoso com transtorno psiquiátrico. $\mathrm{O}$ capítulo de entrevista psiquiátrica traz uma seção sobre avaliação familiar muito útil, além de introduzir algumas das escalas e entrevistas estruturadas mais usadas em pesquisas e mesmo na prática clínica. A última seção deste capítulo trata da transferência e contra-transferência, de maneira breve, mas que certamente será proveitosa na orientação de possíveis problemas na relação médico-paciente.

A segunda parte do livro se concentra na descrição e tratamento dos transtornos psiquiátricos em idosos. O capítulo relativo aos transtornos cognitivos inclui uma extensa e detalhada descrição de subtipos de demência e evolução clínica, além de uma breve discussão de novos achados na genética e fisiopatologia da Doença de Alzheimer, demência vascular, demência por HIV, e o manejo farmacológico das demências. $\mathrm{O}$ capítulo relativo à esquizofrenia e transtornos paranóicos faz um resumo das perspectivas históricas e introduz a questão da distinção entre parafrenia tardia e esquizofrenia paranóide clássica e estados paranóides transitórios. No capítulo relativo aos transtornos de ansiedade e pânico há uma tabela útil resumindo as alternativas e estratégias de tratamento farmacológico. Os transtornos do sono e distúrbios cronobiológicos são abordados de maneira direta e sucinta. Os autores enfatizam a valorização dos distúrbios de sono como sintoma e fator de institucionalização do idoso. Aspectos importantes da psiquiatria geriátrica, o luto e os transtornos de ajustamento são abordados com uma maior profundidade. São discutidas definições de luto "normal" e "anormal", as perdas intra e interpessoais na velhice. Estudos longitudinais de luto, fatores de risco para luto complicado e intervenções terapêuticas são apresentadas. Uma discussão sobre transtornos de ajustamentos encerra o capítulo, ressaltando a raridade de estudos sobre uma condição tão comumente observada em idosos.

A última parte do livro é dedicada ao tratamento dos transtornos psiquiátricos em idosos e inclui capítulos relativos ao tratamento farmacológico, nutrição, dieta e exercícios. No capítulo relativo à psicoterapia é ressaltada a superestimação das dificuldades que nutrem o mito de que os idosos são "rígidos" demais para se beneficiar de uma intervenção psicoterapêutica. As principais modalidades psicoterapêuticas são descritas. $\mathrm{O}$ capítulo sobre o "Continuum de Tratamento: Aproximação com a

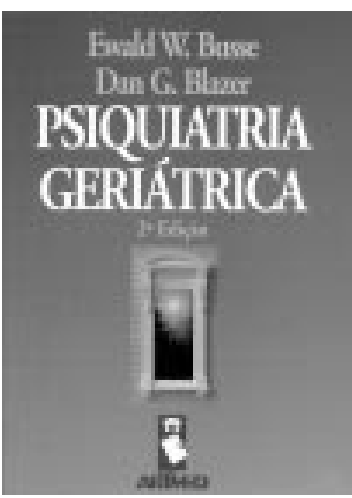
Comunidade" traz uma discussão muito atual sobre a organização e o financiamento dos serviços de saúde para tratamentos de longo prazo, onde "há uma contínua sensação de incapacidade de oferecer atendimento adequado de saúde a custos toleráveis, além de um contínuo interesse em alternativas para a institucionalização".

Em resumo, este livro fornece uma visão abrangente deste crescente campo da psiquiatria geriátrica e certamente interessará àqueles que trabalham com o idoso, mesmo os nãopsiquiatras.

Sérgio Tamai

Universidade de Idosos (Unid), Departamento de Psiquiatria e Psicologia Médica da Faculdade de Ciências Médicas da Santa Casa de São Paulo

\section{O Universo Psicológico do Futuro Médico: Vocação, Vicissitudes e Perspectivas}

Por Luiz Roberto Millan, Orlando Lúcio Neves De Marco, Eneiza Rossi e Paulo Corrêa Vaz de Arruda. 1999. São Paulo: Casa do Psicólogo. 282 páginas. ISBN 85-7396

"Antigamente, a medicina era considerada eminentemente como uma 'arte', um conjunto de conhecimentos pragmáticos e de receitas. Na atualidade ela está em vias de vir a ser a ciência das ciências. Todas as ciências vão, gradativamente, convergir para a sua elevação."

Encontramos esta afirmação no primeiro capítulo deste livro que busca, através dos estudos realizados pelo grupo Grupo de Assistência Psicológica ao Aluno (Grapal) - da Faculdade de Medicina da Universidade de São Paulo, funcionando há 12 anos - , não só avaliar e detectar as dificuldades dos estudantes de medicina, mas também orientá-los e tratá-los através de psicoterapia breve, orientação familiar e grupos de reflexão sobre identidade médica e relação médico-paciente.

No livro, os autores fazem uma gostosa viagem, começando pela vocação médica, falando das aptidões menores com a escolha profissional. São temas sobre os quais os autores levantam hipóteses e sugestões para a continuidade dos 


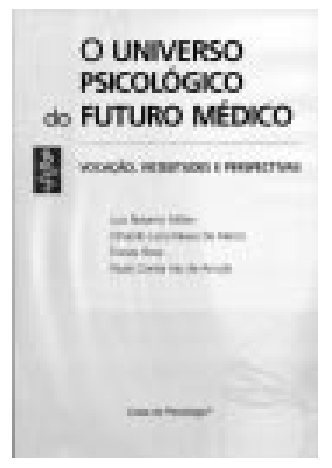

estudos deste tão delicado problema que é o desvendar da vocação médica.

Nos capítulos seguintes, passamos para o curso médico, a dificuldade de se chegar ao curso, o modelo de escolha dos futuros médicos, as novas idéias e novos currículos para a Faculdade de Medicina da Universidade de São Paulo e outras faculdades, assim como outros métodos de aprendizagem. Na conclusão, dados reveladores de uma profissão que coloca o jovem médico em estado de estresse antes mesmo de entrar no mercado de trabalho. As relações entre alunos, professores e pacientes são tratadas de forma clara e objetiva, conceitos são elucidados e distorções são apontadas. Neste capítulo a ética é discutida e é sugerida a sua inclusão em cursos de pós-graduação.

Quando os autores avaliam o estudante de medicina e o seu estado emocional ao longo de três capítulos e culminam com o tratamento nas diversas universidades, mostram-nos uma realidade assustadora, principalmente hoje, onde o acadêmico de medicina é ainda mais jovem e inexperiente. Te- mos distúrbios do comportamento que podem agravar a relação médico-paciente e aumentar os problemas psiquiátricos entre acadêmicos, chegando até os suicidas, já que eles procuram o serviço de aconselhamento somente em períodos de crise. Neste capítulo podemos nos avaliar e reavaliarmos a conduta de colegas que não entendíamos na época da faculdade. Este é um exercício bastante interessante. Quanto a considerações sobre erro médico, a discussão é elucidativa, a conclusão nos leva a reflexões quanto à formação nos cursos de medicina, permitindo que também extrapolemos o assunto para a nossa prática diária.

Finalizando, o livro traz várias entrevistas com professores eméritos que falam de suas vidas como acadêmicos e professores, das quais extraímos lições imediatas. Nas entrevistas com estudantes do primeiro ao sexto ano, temos toda a trajetória de um sonho até o encontro com a realidade que é ser médico. Este livro é uma luz que começa a ganhar força e iluminar um horizonte maior, principalmente neste momento, em que várias faculdades surgem lançando ainda mais jovens no mercado de trabalho.

José Manoel Bombarda

Psiquiatra, membro do Conselho Regional de Medicina do Estado de São Paulo 